\title{
Reduction in Time to Thyroidectomy in Patients Studied with Ultrasound by the Endocrinology Department
}

\author{
Begona Sanchez ${ }^{1}$, Florentino Carral ${ }^{*}$, Carmen \\ Ayala1, Ana Isabel J imenez', Concepcion Garcia', \\ Maria Isabel Robles ${ }^{2}$, Eulalia Porras ${ }^{2}$ and Vicente \\ Vega' \\ ${ }^{1}$ Department of Endocrinology and Nutrition, Hospital \\ Universitario Puerto Real, Spain \\ ${ }^{2}$ Department of General Surgery and \\ Otorhinolaryngology, Hospital Universitario Puerto Real, \\ Spain \\ *Corresponding author: Florentino Carral San \\ Laureano, Endocrinología y Nutrición, Hospital \\ Universitario Puerto Real, Carretera Nacional IV, Km \\ 665. 11510 Puerto Real, Spain
}

Received: July 27, 2017; Accepted: August 24, 2017; Published: September 14, 2017

\begin{abstract}
Objective: To evaluate the time to thyroidectomy in patients with nodular goiter and postoperative tumor stage in patients with Differentiated Thyroid Carcinoma (DTC) depending on the use of ultrasound in endocrinology consultations.
\end{abstract}

Methods: Retrospective and monocentric cohort study of 284 patients (48.7 \pm 13.6 mean age; $84 \%$ women) that underwent thyroidectomy between 2011 and 2014. Time-to-surgery and tumor stage was evaluated in two cohorts: patients examined both in endocrinology (clinical evaluation) and radiology departments (ultrasound and Ultrasound-Guided Fine-Needle Aspiration biopsy (USG-FNA)), and patients examined exclusively in the endocrinology department (clinical evaluation, ultrasound and USG-FNA).

Results: Timeframe from first endocrinology visit until referral for surgery was significantly reduced in the patients studied exclusively in the endocrinology department, both overall ( $40.5 \pm 53.6$ vs $122.7 \pm 77.9$ days; $p<0.001)$ and in patients with suspected DTC (65.1 \pm 104.6 vs $133.5 \pm 79.9$ days; p: 0.024$)$ or confirmed DTC $(65.5 \pm 94.4$ vs $136.4 \pm 80.2$ days; $p: 0.001)$. In DTC patients, there was no difference between groups regarding the size of the primary tumor $(18.0 \pm 11.9$ vs $18.1 \pm 11.0 \mathrm{~mm}$, p: 0.987 ), lymph node extension ( $21 \%$ vs $31 \%)$, distant metastases ( $6 \%$ vs $5 \%$ ) or postoperative tumor stage.

Conclusions: The inclusion of thyroid ultrasound and US-FNA in endocrinology consultations can significantly reduce the clinical study timeframe before surgery, and even without affecting the tumor stage in patients with DTC.

Keywords: Thyroid ultrasound; Endocrinology; Single appointment; ETIEN

\section{Abbreviations}

DTC: Differentiated Thyroid Cancer; ETIEN: Thyroid Ultrasound in Endocrinology; US: Ultrasound; FNA: Fine-Needle Aspiration; USG-FNA: Ultrasound-Guided Fine-Needle Aspiration; RD: RadioDiagnosis; SAEDYN: Andalusian Society of Endocrinology, Diabetes and Nutrition; SEEN: Spanish Society of Endocrinology and Nutrition

\section{Introduction}

Thyroid nodular disease is very common in daily clinical practice. In fact, it is generally detected by means of palpation in $3-7 \%$ of the total population and in $70 \%$ by ultrasound [1-3]. Most thyroid nodules are asymptomatic and benign and, in general, they only require observation and follow-up. However, some thyroid nodules grow, become symptomatic and require treatment, generally surgery $[4,5]$. On the other hand, around 5\% of thyroid nodules are malignant and the patient also needs to undergo a thyroidectomy [6-8]. Therefore, the main challenges when facing a patient with a thyroid nodular disease are to establish whether the lesion is malignant or benign and to offer the most suitable treatment in each case, depending on the diagnosis, clinical suspicion, size of the nodules and functionality.

Thyroid ultrasound is the most important diagnostic imaging technique when evaluating a thyroid nodular disease given its high sensitivity in detecting thyroid nodules, its convenience when carrying out measurements, its high specificity to identify malignant nodules and its use as a guide when carrying out an Ultrasound-Guided Fine-Needle Aspiration biopsy (USG-FNA) of thyroid nodules and/ or suspicious cervical lymph nodes [9-14]. In our country, the vast majority of thyroid ultrasounds and USG-FNAs are performed by radiologists of diagnostic radiology departments [15-17]. There are few endocrinology departments (even if they are ever-growing) where the ultrasound is performed by the endocrinologists themselves in a single appointment [18]. In these cases, it is even possible to carry out a USG-FNA of thyroid nodules or suspicious lymph nodes in the same consultation [19-24].

We currently have little information on whether the time to establish and offer the most appropriate treatment for patients with thyroid nodular disease would be affected if performed by an endocrinologist. There is currently only one publication in our country that demonstrates a reduction in time-to-surgery in these patients. Moreover, in the case of Differentiated Thyroid Carcinoma (DTC), it is recommended to optimize study and treatment times $[6,25]$. With an early diagnosis, it is more likely for the cancer to be restricted to the thyroid gland and, therefore, only surgical treatment necessary, resulting in a decrease of the relapse rate and the associated mortality [26]. Hence, the objective of our research has been to determine whether the use of thyroid ultrasound and USG-FNA of thyroid nodules in endocrinology consultations is able to reduce the 
Table 1: Time to thyroidectomy in patients examined in single appointment of endocrinology or jointly in endocrinology and radio-diagnosis.

\begin{tabular}{|c|c|c|c|}
\hline Patients & Study in single appointment of endocrinology & Endocrine and RD study & $\mathbf{P}$ \\
\hline $\begin{array}{c}\text { All the patients } \\
\mathrm{N} \text { (\% of total patients) } \\
\text { Endocrine consultations }(\mathrm{n}) \\
\text { Time } 1 \text { (days) } \\
\text { Time } 2 \text { (days) } \\
\text { Time } 3 \text { (days) } \\
\text { Total time (days) }\end{array}$ & $\begin{array}{c}139(100 \%) \\
2.0 \pm 0.8 \\
28.5 \pm 12.1 \\
40.5 \pm 53.6 \\
174.0 \pm 110.6 \\
247.9 \pm 115.8\end{array}$ & $\begin{array}{c}145(100 \%) \\
2.7 \pm 0.8 \\
32.0 \pm 28.4 \\
122.7 \pm 77.9 \\
205.4 \pm 139.5 \\
353.8 \pm 116.1\end{array}$ & $\begin{array}{c}- \\
<0.001 \\
0.301 \\
<0.001 \\
0.045 \\
<0.001\end{array}$ \\
\hline $\begin{array}{l}\text { Patients suspicious of DTC cytology } \\
\mathrm{N}(\% \text { of total patients) } \\
\text { Endocrine consultations ( } \mathrm{n}) \\
\text { Time } 1 \text { (days) } \\
\text { Time } 2 \text { (days) } \\
\text { Time } 3 \text { (days) } \\
\text { Total time (days) }\end{array}$ & $\begin{array}{c}18(13 \%) \\
2.1 \pm 1.4 \\
27.0 \pm 11.0 \\
65.1 \pm 104.6 \\
37.3 \pm 18.1 \\
134.6 \pm 129.8\end{array}$ & $\begin{array}{c}25(17 \%) \\
2.7 \pm 0.8 \\
28.3 \pm 10.0 \\
133.5 \pm 79.9 \\
60.5 \pm 42.9 \\
211.1 \pm 103.2\end{array}$ & $\begin{array}{l}0.679 \\
0.076 \\
0.695 \\
0.024 \\
0.037 \\
0.042\end{array}$ \\
\hline $\begin{array}{c}\text { Patients with confirmed DTC } \\
\mathrm{N}(\% \text { of total patients) } \\
\text { Endocrine consultations (n) } \\
\text { Time } 1 \text { (days) } \\
\text { Time } 2 \text { (days) } \\
\text { Time } 3 \text { (days) } \\
\text { Total time (days) }\end{array}$ & $\begin{array}{c}33(24 \%) \\
2.2 \pm 1.0 \\
24.0 \pm 9.8 \\
65.5 \pm 94.4 \\
90.7 \pm 93.8 \\
180.6 \pm 132.0\end{array}$ & $\begin{array}{c}39(27 \%) \\
2.8 \pm 0.7 \\
35.8 \pm 43.4 \\
136.4 \pm 80.2 \\
149.2 \pm 134.7 \\
302.0 \pm 164.9\end{array}$ & $\begin{array}{l}0.988 \\
0.002 \\
0.133 \\
0.001 \\
0.040 \\
0.002\end{array}$ \\
\hline $\begin{array}{l}\text { Patients with benign lymph node pathology } \\
\mathrm{N} \text { (\% of total patients) } \\
\text { Endocrine consultations }(\mathrm{n}) \\
\text { Time } 1 \text { (days) } \\
\text { Time } 2 \text { (days) } \\
\text { Time } 3 \text { (days) } \\
\text { Total time (days) }\end{array}$ & $\begin{aligned} & 106 \\
& 1.9 \pm 0.8 \\
& 28.4 \pm 11.7 \\
& 29.8 \pm 26.8 \\
& 204.3 \pm 101.5 \\
& 269.8 \pm 102.7\end{aligned}$ & $\begin{array}{c}106 \\
2.7 \pm 10.8 \\
30.7 \pm 36.9 \\
117.5 \pm 77.2 \\
226.8 \pm 136.0 \\
373.6 \pm 163.6\end{array}$ & $\begin{array}{c}<0.001 \\
0.572 \\
<0.001 \\
0.188 \\
<0.001\end{array}$ \\
\hline
\end{tabular}

N: Number; DTC: Differentiated Thyroid Cancer; RD: Radio-Diagnosis

Time 1: days from the referral from primary care physician to the first visit with the endocrinologist; Time 2: days from the first endocrinology consultation to the endocrinology consultation when the patient is referred to surgery; Time 3: days from the referral to surgery to the performance of the thyroidectomy; Total time: days from the referral from primary care to thyroidectomy.

clinical study timeframe before thyroidectomy and whether it affects the tumor stage in patients with DTC.

\section{Material and Methods}

\section{Study design}

The ETIEN study (Thyroid Ultrasound in Endocrinology) was designed as a prospective study to assess the clinical results and the healthcare and economic impact of the implementation of the thyroid ultrasound in endocrinology consultations of the Hospital Universitario Puerta Real (Cadiz, Spain). The results of the sub-study ETIEN 1 regarding the economic impact of this strategy have been recently published [27]. The sub-study ETIEN 2 is a retrospective cohort study, which aims to evaluate the time to thyroidectomy in patients with nodular goiter and the tumor stage in patients with DTC according to whether the ultrasound study has been conducted in a diagnostic radiology department or in endocrinology consultations.

\section{Assessment of the thyroid nodular disease}

Since 2010, in our hospital a thyroid nodule management protocol exists that involves the endocrinology, diagnostic radiology, general surgery and pathology departments, all of them coordinated by the thyroid disease monographic consultation of our department. These protocols have been reviewed in 2012 and 2014, and are annually evaluated (since 2010) by monitoring quality indicators, amongst which time-to-thyroidectomy is included.

Until January 2013, all thyroid ultrasounds and USG-FNA in patients with thyroid nodular disease were carried out in the diagnostic radiology department of our hospital. From that date on, however, single-appointment thyroid ultrasounds in the endocrinology consultations were progressively introduced, so that by $2014,81 \%$ of all thyroid ultrasounds were conducted by endocrinologists in their consultations. All the ultrasounds of our department have been done with a Sonosite Micromax portable digital ultrasound machine with a 6-13-Mhz linear array broadband transducer. Since 2013, the majority of thyroid USG-FNAs has been carried out in our consultations, even though it was performed by the diagnostic radiology department in some patients. Patients with thyroid nodular disease who were candidates to undergo a thyroidectomy due to suspicion of DTC, those with large thyroid nodules or large goiters, and those presenting significant cervical symptoms were referred to a surgery consultation to evaluate and schedule the thyroidectomy, prioritizing those DTCsuspicious patients.

\section{Patient selection}

Patients who underwent a thyroidectomy for benign nodular goiter or DTC (papillary or follicular) between 2011 and 2014 and that had been previously examined in the thyroid disease monographic consultation of the endocrinology department of our hospital were eligible for inclusion in the study. The patients were classified into a) patients examined in endocrinology: those who had attended the clinical consultation and undergone a thyroid ultrasound and USG-FNA (if performed) exclusively by an endocrinologist, and b) patients examined both in endocrinology and diagnostic radiology departments: those examined in endocrinology, whose ultrasound study and/or the USG-FNA were carried out by the diagnostic radiology department. The following groups of patients were excluded: those who had not been fully examined in our department; those who had had an ultrasound study conducted both by the endocrinologist and the radiologist; those who had undergone surgery due to Graves' 
Table 2: Clinical characteristics and tumor stage in DTC patients based on the AJCC-TNM Staging Manual, $7^{\text {th }}$ edition [23].

\begin{tabular}{|c|c|c|c|}
\hline Patients & Endocrine single appointment & Endocrine and RD study & $\mathbf{P}$ \\
\hline Patients with confirmed DTC (\%) & $33(23.7 \%)$ & $39(26.9 \%)$ & 0.988 \\
\hline Age when diagnosed (years old) & $44.1 \pm 13.0$ & $46.1 \pm 15.2$ & 0.548 \\
\hline Gender (\% of women) & $81.8 \%$ & $86.4 \%$ & 0.592 \\
\hline Main tumor's size (mm) & $18.0 \pm 11.9$ & $18.1 \pm 11.0$ & 0.987 \\
\hline $\begin{array}{c}\text { Stage T }(\%) \\
\text { TX } \\
\text { T1 } \\
\text { T2 } \\
\text { T3 } \\
\text { T4 }\end{array}$ & $\begin{array}{c}0(0 \%) \\
22(67 \%) \\
7(21 \%) \\
3(9 \%) \\
1(3 \%)\end{array}$ & $\begin{array}{c}0(0 \%) \\
19(48 \%) \\
10(26 \%) \\
7(18 \%) \\
3(8 \%)\end{array}$ & 0.518 \\
\hline $\begin{array}{c}\text { Stage N } \\
\text { NX } \\
\text { No } \\
\text { N1 }\end{array}$ & $\begin{array}{c}2(6 \%) \\
24(73 \%) \\
7(21 \%)\end{array}$ & $\begin{array}{c}0(0 \%) \\
27(69 \%) \\
12(31 \%)\end{array}$ & 0.444 \\
\hline $\begin{array}{c}\text { Stage M } \\
\text { MX } \\
\text { M0 } \\
\text { M1 }\end{array}$ & $\begin{array}{c}2(6 \%) \\
29(88 \%) \\
2(6 \%)\end{array}$ & $\begin{array}{c}0(0 \%) \\
37(95 \%) \\
2(5 \%)\end{array}$ & 0.813 \\
\hline $\begin{array}{c}\text { Stage TNM } \\
\text { Stage I } \\
\text { Stage II } \\
\text { Stage III } \\
\text { Stage IV }\end{array}$ & $\begin{array}{c}27(82 \%) \\
1(3 \%) \\
2(6 \%) \\
3(9 \%)\end{array}$ & $\begin{array}{c}31(79 \%) \\
2(5 \%) \\
2(5 \%) \\
3(11 \%)\end{array}$ & 0.860 \\
\hline
\end{tabular}

mm: millimeters; DTC: Differentiated Thyroid Cancer; RD: Radio-Diagnosis;

$\mathrm{S}$ : Size of the tumor; N: Central, lateral cervical and superior medial compartment lymph nodes; M: Distant metastases

disease, toxic nodular or multi-nodular goiter and medullary or anaplastic thyroid carcinoma; and those cases in which either the patient or the surgeon decided to postpone the surgery.

\section{Study variables}

The variables analyzed in our study were age, gender, number of consultations in endocrinology, time to thyroidectomy, results of the thyroid cytology, definite anatomopathological diagnosis, tumor size (the largest nodule in the case of several DTC sites) and tumor stage (in patients with DTC). Tumor staging was based on the $7^{\text {th }}$ edition of the American Joint Committee on Cancer Staging Manual (AJCCTNM, $7^{\text {th }}$ edition) [28]. Time to thyroidectomy was measured in days and was sub-divided into three periods: days from primary care physician referral to the first visit with the endocrinologist (time 1); days from the first endocrinology consultation to the endocrinology consultation in which the patient is referred for surgery (time 2); and days from referral for surgery to thyroidectomy (time 3). In our study, the large majority of cytologies were classified following international recommendations [29], and those cytologies classified under the Bethesda guidelines were few [30]. In a practical way, we have considered as a suspicious malignant cytology only those labeled as "malignant" or "suspicious for malignancy", or those patients with suspicious cervical lymph nodes classified as "consistent with metastasis from papillary thyroid carcinoma".

The differences between the groups (ultrasound in endocrinology or ultrasound in diagnostic radiology) have been analyzed considering the clinical features, number of endocrinology consultations required and time to thyroidectomy, both globally and in patients with a suspicious for malignancy cytology or with confirmed DTC. These patients also underwent an evaluation regarding the differences in tumor size in millimeters, $\mathrm{T}$ stage (size of the primary tumor), $\mathrm{N}$ stage (number of regional lymph nodes affected), $\mathrm{M}$ stage (presence of distant metastasis), and TNM stage.

\section{Statistical analysis}

Data was included and analyzed with SPSS 12.0 data analysis software for Windows. The descriptive analysis of the qualitative variables was carried out calculating the frequencies and percentages, whereas for the quantitative variables, the average, the standard deviation, the median and the range were determined. After checking the assumption of normality in the sample with the Shapiro-Wilk test, the following tests were conducted: Student's t-test to compare quantitative variables amongst independent groups, chi-square test to compare qualitative variables amongst independent groups and, when indicated, ANOVA test. All the signification values refer to the two-tailed test, association being statistically significant when $\mathrm{p}$ $<0.05$.

\section{Results}

367 patients who had undergone a thyroidectomy in our center between 2011 and 2014 were examined, $77.4 \%$ of which (284 patients) met the study inclusion criteria. The following patients were excluded: 34 patients with thyroid ultrasound performed by both endocrinology and diagnostic radiology departments, 27 patients with Graves's disease or toxic nodular or multi-nodular goiter, 16 patients where surgery was postponed either by decision of the surgeon or of the patients themselves, 5 patients examined in other departments and one patient with medullar thyroid cancer. Regarding the patients included in the analysis, no statistically significant differences were observed in the mean age at the time of surgery (48.0 \pm 13.0 vs $49.4 \pm 14.5$ years; p: 0.409$)$ or in the gender distribution ( $83.4 \%$ vs $84.6 \%$ women; p: 0.323 ) among those patients examined solely in endocrinology (n: 139) and those examined both in endocrinology and diagnostic radiology (n: 145).

Table 1 shows the time to thyroidectomy in both studied groups. The time from the first endocrinology consultation to the referral for surgery (time 2) was reduced in the group of patients whose 
ultrasound was performed in endocrinology consultation, both globally ( $40.5 \pm 53.6$ vs $122.7 \pm 77.9$ days; $\mathrm{p}<0.001)$, and in patients with suspected DTC $(65.1 \pm 104.6$ vs $133.5 \pm 79.9$ days; p: 0.024$)$, with confirmed DTC $(65.5 \pm 94.4$ vs $136.4 \pm 80.2$ days; p: 0.001$)$ or with a benign nodular disease $(29.8 \pm 26.8$ vs $117.5 \pm 77.2$ days; $\mathrm{p}<0.001)$. This led to a mean time reduction of the clinical study timeframe in endocrinology consultations of $67 \%, 51 \%, 52 \%$ and $74 \%$ in all patients, patients with suspicious for malignancy cytology, patients with confirmed DTC, and patients with benign nodular disease, respectively. Furthermore, the patients whose ultrasound was performed in the endocrinology consultation needed fewer consultations in the endocrinology department in general and in the sub-groups, although within the DTC-suspected patients this difference did not reach statistical significance (Table 1).

During the study period, a total of 72 patients were diagnosed with DTC (25.4\% of the assessed thyroidectomies), with a similar distribution between the groups of patients evaluated in a single endocrinology appointment (33 patients; $24 \%$ of the total) and those evaluated jointly in the endocrinology and diagnostic radiology departments (39 patients; $27 \%$ of the total). Globally, the total time to thyroidectomy was higher in the confirmed DTC group, compared with the suspicious for malignancy cytology group (39 patients), since this includes patients with previous benign cytology (9 patients), follicular proliferation cytology (19 patients) or without cytology (5 patients). As shown in Table 2, no statistically significant differences were observed in the clinical features, tumor size, extension to lymph nodes, distant metastasis or tumor stage among the groups assessed. Nonetheless, the time from primary care referral to surgery in patients with confirmed lymph node involvement (19 patients) was lower $(161.2 \pm 134.9$ vs $257.2 \pm 152.2$ days; p: 0.041$)$ than in those patients with no lymph node involvement (51 patients).

\section{Discussion}

The delays when being admitted to the public health system constitute an important problem nowadays, especially in our country. It is therefore essential to look for feasible and efficient alternatives. Most healthcare authorities consider that these solutions require a change in the health organization, new management models, greater flexibility and, specially, the involvement of professionals in the organization's goals [31]. The recently published ETIEN 1 study showed that in our area, ultrasounds carried out in the endocrinology consultations in a single appointment could contribute to a significant economic saving [27]. The results of the ETIEN 2 study presented here show that this strategy also allows reducing $67 \%$ on average the days needed for study in endocrinology consultations, and 30\% the days from primary care physician referral until the surgery is performed.

We can currently confirm (with a moderate to high level of evidence) that the DTC diagnosis in initial stages is associated with a less extensive and aggressive surgery, with less risk of relapse and mortality, and with the need of lower doses of I-131 and, consequently, less risk of developing other malignant neoplasms associated with radiation [26,32]. Thus, several organizations such as the British Thyroid Association, recommend the adaptation of clinical study timeframe in DTC patients, so that the time elapsed from the urgent referral of the patient until the completion of the first definite treatment is less than 62 days $[6,25]$. In our case, given the single appointment strategy in endocrinology consultations, we have managed to halve the clinical study timeframe in patients with a suspicious for malignancy cytology or with confirmed DTC (even though it is still far from standards), although this decrease did not mean smaller tumor size or extension. In fact, DTC patients with lymph node involvement confirmed postoperatively, spent less time waiting to undergo surgery than those with no lymph node involvement, since most of these patients were suspected of having DTC before surgery and they were prioritized for surgery.

Our study has some limitations: first of all, the observed differences in times to thyroidectomy between two cohorts of nonsimultaneous patients $(100 \%$ of patients studied with ultrasound in endocrinology underwent surgery in 2013 and 2014, and $80.5 \%$ of those with the ultrasound carried out in diagnostic radiology did so in 2012 and 2013) should be interpreted carefully. Nonetheless, the significant drop in the mean number of endocrinology consultations before referral for surgery between groups suggests that the temporary differences observed in favour of the single appointment may be close to reality. Secondly, we are aware that the time reduction until surgery may depend on many factors beyond those analyzed in our work [20]. Accordingly, we have observed a progressive decrease in days from referral by the endocrinology department to thyroidectomy since 2010, due to a better coordination between departments and the implementation of an ongoing improvement strategy of timing to thyroidectomy, having a more visible impact on the patients examined in single endocrinology appointment, since these patients underwent surgery mostly in 2013 and 2014, period in which the surgical waiting times were shorter.

In the single appointment consultation, the endocrinologist integrates the patient's clinical, hormonal and ultrasound data in a single encounter. In this visit, the specialist decides which therapeutic attitude is the most convenient. This has demonstrated to be a costeffective and efficient approach when reducing the waiting times [20]. Furthermore, it has improved the health system efficiency in comparison to the traditional outpatient care systems [27]. Moreover, it may also increase patient satisfaction, as the waiting times are dramatically shortened, costs associated to consultations are reduced and the anxiety caused by the delay in the diagnosis and its treatment is minimized, without the need for a special infrastructure or technological investment.

In conclusion, the integration of clinical and ultrasound evaluation in endocrinology consultations has led to a statistically significant drop in the time needed to diagnose patients with a benign or malignant thyroid nodular disease, which has contributed to a meaningful reduction of the time to thyroidectomy.

\section{Statement of the Authors}

- Drs. Carral and Sánchez are responsible for the design, gathering, analysis and interpretation of the data and original writing of the article.

- Drs. Ayala, Jiménez and García have participated in the clinical care of the studied patients, data gathering, critical review, correction of the article and approval of its final version for publication. 
- Drs. Robles, Vega and Porras have participated in the surgical treatment of the studied patients and in the critical review of the final version for its publication.

\section{Funding}

This work has received funding from the Research Grant SAEDYN 2013 and the SEEN Foundation Grant for Research in Thyroid Pathology 2015.

\section{Conflict of Interests}

The authors of this study declare that this manuscript is original, has not been submitted to another journal and has never been published elsewhere. The authors have no conflicts of interest to disclose.

\section{References}

1. Gharib H, Papini E. Thyroid nodules: Clinical importance, assessment, and treatment. Endocrinol Metab Clin North Am. 2007; 36: 707-735.

2. Guth S, Theune U, Aberle J, Galach A, Bamberger CM. Very high prevalence of thyroid nodules detected by high frequency $(13 \mathrm{MHz})$ ultrasound examination. Eur J Clin Invest. 2009; 39: 699-706.

3. Hoang JK, Lee WK, Lee M, Johnson D, Farrell S. US Features of thyroid malignancy: pearls and pitfalls. Radiographics. 2007; 27: 847-860.

4. Hegedus L. The thyroid nodule. N Eng J Med. 2004; 351: 1764-1771.

5. Filetti S, Durante C, Torlontano M. Nonsurgical approaches to the management of thyroid nodules. Nat Clin Pract Endocrinol Metab. 2006; 2: 384-394.

6. The British Thyroid Association. Thyroid Association Guidelines for the Management of Thyroid Cancer. Clinical Endocrinol. 2014: 1-156.

7. Haugen BR, Alexander EK, Bible KC, Doherty GM, Mandel SJ, Nikiforov YE, et al. The American Thyroid Association (ATA). 2015 American Thyroid Association Management Guidelines for Adult Patients with Thyroid Nodules and Differentiated Thyroid Cancer. Thyroid. 2016; 26: 1-133.

8. Gharib H, Papini E, Paschke R, Duick DS, Valcavi R, Hegedus L, et al 2010 American Association of Clinical Endocrinologists, Associazione Medici Endocrinologi, and European Thyroid Association Medical guidelines for clinical practice for the diagnosis and management of thyroid nodules: executive summary of ecommendations. Endocr Pract. 2010; 16:468-475.

9. Frates MC, Benson CB, Charbonneau JW, Cibas CS, Clark OH, Coleman BG, et al. Management of thyroid nodules detected at US: society of radiologists in ultrasound consensus statement. Radiology. 2005; 237: 794-800.

10. Hegedus L. Thyroid ultrasound. Endocrinol Metab Clin North Am 2001; 30: 339-360.

11. Moon WJ, Jung SL, Lee JH, Na DG, Baek JH, Lee YH, et al. Benign and malignant thyroid nodules: US differentiation-multicenter retrospective study. Radiology. 2008; 247: 762-770.

12. Horvath E, Majlis S, Rossi R, Franco C, Niedmann JP, Castro A, et al. An Ultrasonogram Reporting System for Thyroid Nodules Stratifying Cancer Risk for Clinical Management. J Clin Endocrinol Metab. 2009; 90: 748-751.

13. Tae HJ, Lim DJ, Baek KH, Park WC, Lee YS, Choi JE, et al. Diagnostic value of ultrasonography to distinguish between benign and malignant lesions in the management of thyroid nodules. Thyroid. 2007; 17: 461-466.

14. Kwak J, Han K, Yoon J, Moon H, Son E, Park S, et al. Thyroid Imaging Reporting and Data System for US Features of Nodules: A Step in Establishing Better Stratification of Cancer Risk. Radiology. 2011: 260: 892-899.
15. Sanmarti A. Use of "specific" techniques in endocrinology and nutrition. Endocrinol Nutr. 2005; 52: 267-272.

16. Fernández JC, Mancha I, Ortega MV, Ruiz JF, Castells I, Tofé S, et al. Diagnostic and functional structure of a high-resolution thyroid nodule clinic: An efficiency model. Endocrinol Nutr. 2014; 61: 329-334.

17. Sebastián N, Fernández JC, Mancha I, Sebastián A, Fernández D, Ortega $\mathrm{MV}$, et al. Clinical experience in a high-resolution thyroid nodule clinic. Endocrinol Nutr. 2011; 58: 409-415.

18. Brennan MD, Miner KM, Rizza RA. Profiles of the endocrine clinic. The Mayo Clinic. J Clin Endocrinol Metab. 1998; 83: 3427-3434.

19. Tofe S, Arguelles I, Garcia H, Quevedo J, Diaz S, Serra G, et al. Routine performance of thyroid ultrasound and fine-needle aspiration biopsy in the setting of a high-resolution endocrinology practice. Endocrinol Nutr. 2010; 57: 43-48.

20. Castells I, Pardo N, Videla S, Jimenez G, Llargues E, Simo O, et al. Healthcare impact of introduction of thyroid ultrasound in a thyroid nodule pathology unit. Endocrinol Nutr. 2013; 60: 53-59.

21. Martin T, Torres A, Yanez P, Gentil A, Diaz M, Lopez F, et al. Utilidad de la determinacion de tiroglobulina en aspirado de ganglios linfaticos de pacientes con cancer papilar de tiroides y Ac antitiroglobulinicos positivos. Endocrinol Nutr. 2009; 56; 447-451.

22. Maldonado GF, Irigoyen L, Torres B, Arrizabalaga JJ. Atencion integral en la patologia tiroidea nodular: hacia la unificacion de recursos y la consulta de alta resolucion. III Congreso nacional de atencion sanitaria al paciente cronico. 2009.

23. Penin M, San Miguel P, Seoane I, Cunqueiro R, Palmeiro R, Luna R. Needle washing increases the diagnostic yield of fine needle aspiration biopsy of the thyroid gland. Endocrinol Nutr. 2013; 60: 115-118.

24. Bukhari MH, Niazi S, Hanif G, Qureshi SS, Munir M, Hasan M, et al. An updated audit of fine needle aspiration cytology procedure of solitary thyroid nodule. Diagn Cytopathol. 2008; 36: 104-112.

25. Department of Health. Cancer Waiting Times: A Guide (Version 5). 2006

26. Clement SC, Kremer LC, Links TP, Mulder RL, Ronckers CM, van Eck-Smit $\mathrm{BL}$, et al. Is outcome of differentiated thyroid carcinoma influenced by tumor stage at diagnosis? Cancer Treat Rev. 2015; 41: 9-16.

27. Carral F, Ayala MC, Jimenez Al, Garcia C. Care and economic impact of thyroid ultrasound examination at single visits to endocrinology clinics (the ETIEN 1 study). Endocrinol Nutr. 2016; 63: 64-69.

28. Sobin LH, Gospodarowicz MK, Wittekind C. TNM Classification of Malignant Tumours ( $7^{\text {th }}$ edition). Wiley-Blackwell, Oxford. 2009.

29. Cibas ES, Ali SZ. The Bethesda System for Reporting Thyroid Cytopathology. Am J Clin Pathol. 2009; 132: 658-665.

30. Cooper DS, Doherty GM, Haugen BR, Kloos RT, Lee SL, Mandel SJ, et al. Revised American Thyroid Association Management Guidelines for Patients with Thyroid Nodules and Differentiated Thyroid Cancer. Thyroid 2009; 19: 1167-1214.

31. Juan FJ, Aranda G, Trujillo J. High resolution, patients, relatives and organizational innovation. Rev Adm Sanit. 2007; 5: 105-121.

32. Lang BH, Ng SH, Lau LL, Cowling BJ, Wong KP, Wan KY. A systematic review and meta-analysis of prophylactic central neck dissection on shortterm locoregional recurrence in papillary thyroid carcinoma after total thyroidectomy. Thyroid. 2013; 23:1087-1098.
Annals Thyroid Res - Volume 3 Issue 2 - 2017

Submit your Manuscript | www.austinpublishing group.com

Carral et al. (C) All rights are reserved
Citation: Sanchez B, Carral F, Ayala C, Jimenez Al, Garcia C, Robles MI, et al. Reduction in Time to Thyroidectomy in Patients Studied with Ultrasound by the Endocrinology Department. Annals Thyroid Res. 2017; 3(2): 115-119. 